\title{
COM, CONTRA E PARA ALÉM DE CHARLES TILLY: MUDANÇAS TEÓRICAS NO ESTUDO DAS AÇÕES COLETIVAS E DOS MOVIMENTOS SOCIAIS ${ }^{1}$
}

\section{INTRODUÇÃO}

Em abril de 2008 faleceu o norte-americano Charles Tilly, um dos cientistas sociais mais prolíficos dos últimos tempos. Dos seus mais de cinquenta livros (o primeiro deles, The vendée, publicado em 1964 e o último, Contentious performances, publicado em 2008) e entre 600 e 700 artigos publicados ${ }^{2}$ é habitual destacar suas contribuições ao debate sobre mudança social na Europa, em particular no Reino Unido e na França, a partir de 1650, seus aportes seminais sobre a análise histórica nas ciências sociais, assim como sua importante contribuição teórica e metodológica ao debate sobre Estado, nacionalismo, conflito, violência coletiva, ações coletivas e movimentos sociais. Apesar de ter vários livros traduzidos para francês, espanhol, italiano, alemão, grego, chinês, japonês, coreano, árabe, russo, polonês, checo, turco e artigos em muitos outros idiomas, somente um livro (Coerção, capital e estados europeus, de 1990, traduzido pela Coleção Clássicos da Edusp, em 1996), além de dois artigos, "Itinerários em análise social" (Tilly, 2004) e "O acesso desigual ao conhecimento científico" (Tilly, 2006) e uma entrevista (Alonso \& Araújo, 2004) haviam sido publicados no Brasil até recentemente. ${ }^{3}$ Nenhum deles aborda de forma direta a temática da ação coletiva e dos movimentos sociais. Contudo, nos últimos quatro anos, justamente após sua morte, parece iniciar-se no Brasil um "diálogo póstumo" com o autor a partir da discussão de seus textos, apresentações de trabalhos em congressos e a reprodução de artigos que abordam os movimentos sociais e a contestação política, tais como "Mapear o confronto político" (Lua Nova, 2009, 76) e "Movimentos sociais como política" (Revista Brasileira de Ciência Política, 2010, 3).4

Há várias explicações possíveis tanto para o olvido prévio como para a recuperação recente do autor. A partir de um diálogo com Tarrow (2011) em sua visita recente ao Brasil, argumentei por que as teorias norte-americanas tiveram até recentemente um impacto indireto, tardio e parcial no debate brasileiro - e latino-americano de forma mais ampla - sobre as ações coletivas e os movimentos sociais e como esse cenário começa a se transformar (Bringel, 
2011a). A confluência de fatores tais como o anti-imperialismo latino-americano, o estruturalismo na tradição da teoria social regional, a resistência à "morte" do marxismo tal como decretada por muitos, a influência de Alain Touraine e colaboradores através das teorias dos "novos movimentos sociais" (mais próximos inclusive fisicamente ao debate nacional e regional) e a escassa preocupação, em termos empíricos, pela América Latina dos teóricos dos movimentos sociais norte-americanos, certamente contribuíram para que, até os anos 1990, a teoria da mobilização dos recursos e a teoria do processo político tivessem pouca entrada nos debates sobre o ativismo brasileiro e regional. Além disso, a construção de uma dupla fratura ontológica entre as interpretações norte-americanas (consideradas mais "institucionalistas" e com uma particular ênfase nas estruturas) e as europeias (vistas como mais "culturalistas" e com mais foco na "ação") levou a que esta segunda fosse mais atrativa para um contexto brasileiro de transição política à democracia em que a "autonomia" era uma palavra-chave. ${ }^{5}$

No entanto, em meados da década de 1990, enquanto o estudo dos movimentos sociais, em um sentido mais estrito, sofria uma espécie de letargia no Brasil devido a um desvio das lentes analíticas para outros temas afins como a participação, a esfera pública e a sociedade civil entendida de forma ampla e, em parte, a uma incapacidade para gerar análises compreensivas sobre as novas configurações contestatórias, ${ }^{6}$ um relevante grupo de estudiosos das ações coletivas e dos movimentos sociais nos Estados Unidos - liderado pelo próprio Tilly, com a companhia de Tarrow e McAdam - buscava configurar uma nova agenda de pesquisa sobre as ações coletivas. Começava a se configurar uma agenda mais ampla e com um caráter dinâmico e relacional. Os desdobramentos destas novas propostas teórico-metodológicas, com grande repercussão internacional, não foram debatidos de forma sistemática no Brasil. E quando começam a ser discutidas hoje, parecem descuidar os pilares básicos que as sustentam.

Este texto pretende contribuir, de forma inicial e inevitavelmente parcial, para esta tarefa a partir da discussão crítica do legado de Charles Tilly no estudo das ações coletivas e da contestação política, de forma geral, e dos movimentos sociais, de maneira mais específica, a partir de uma tripla direção: primeiro, “com Tilly", resgatando suas principais contribuições teórico-metodológicas neste campo; segundo, "contra Tilly", discutindo tanto as principais críticas recebidas e controvérsias com outras teorias, escolas e autores, como a busca de respostas renovadas por parte do autor; e, finalmente, "para além de Tilly", assinalando alguns elementos relevantes que se desprendem de sua obra recente e como recuperá-los/superá-los a partir de alguns desafios abertos no estudo das ações coletivas e dos movimentos sociais contemporâneos. Com isto, pretende-se destacar tanto os aportes "clássicos" do autor no estudo das ações coletivas (deixando de fora, devido ao recorte escolhido, suas contribuições para outros debates e campos), como também mapear brevemente sua trajetória recente 
que supõe, em vários aspectos, um autêntico exercício de reflexão do autor sobre sua trajetória anterior, ademais de uma tentativa, conforme mencionado anteriormente, de renovação da agenda de pesquisa sobre as ações coletivas. Além disso, ainda que o artigo tome como eixo central o pensamento de Tilly, procura ir além de sua obra, trazendo à tona alguns dos desafios teóricos centrais no estudo das ações coletivas e movimentos sociais contemporâneos.

\section{COM TILLY: CONTRIBUIÇÕES TEÓRICO-METODOLÓGICAS “CLÁSSICAS”}

Uma das características mais destacadas e recorrentes na obra de Charles Tilly foi sua capacidade de imbricar a história com a sociologia, assim como sua facilidade para relacionar seus diferentes objetos de estudo, tornando certamente complexa uma demarcação estrita de seus aportes no campo das ações coletivas e dos movimentos sociais. No que se refere ao primeiro aspecto, Tilly sempre dedicou uma atenção especial a este encontro disciplinar, chegando a publicar um livro sobre o tema, As sociology meets history (Tilly, 1981), no qual busca explicar como se posicionar dos "dois lados das fronteiras", tanto no terreno da história (e de uma reconstrução da historiografia hegemônica) como da sociologia, mas, sobretudo, "na fronteira", nos âmbitos de convergência entre ambos, ou seja, na sociologia histórica, apesar de manifestar seu desacordo com as propostas que fazem emergir subdisciplinas a partir de técnicas e enfoques, e não de temáticas teóricamente coerentes. Por outro lado, no que se refere aos principais âmbitos de contribuição, podemos situar, seguindo Aguilar (2009), três grandes campos: a metodologia macrossociológica e a histórica comparada, sua inovadora forma de analisar os conflitos sociais e o estudo das ações coletivas e dos movimentos sociais per se.

Os primeiros esforços mais sistemáticos de Charles Tilly no campo da ação coletiva são os seus estudos sobre a formação do Estado, como The formation of national states in Western Europe (Tilly, 1975), onde, recuperando ideias-chave de Michael Mann e Barrington Moore Jr, sugere uma relação entre a formação dos Estados europeus e a guerra para assegurar a defesa de seus territórios, o que poderia fortalecer ou debilitar o Estado. Em Coerção, capital e estados europeus (Tilly, 1992) aprofunda em dois modos particulares que levam à formação do Estado: o conflito e a guerra, sempre presentes mediante uma dialética que varia entre a utilização intensiva da coerção ou a utilização intensiva do capital. Destacam-se nesses estudos de Tilly as várias formas possíveis de manifestação de alianças e conflitos entre grupos sociais. O estudo do conflito, da violência política e da ação coletiva aparece assim como elemento central para sugerir que os processos de formação do Estado foram muito mais contingentes, transitórios e reversíveis do que o sugerido anteriormente pelos estudiosos prévios do desenvolvimento político do Estado. 
Uma segunda contribuição fundamental desta primeira etapa de Tilly consiste em que, enquanto a maioria da literatura histórica documentava e analisava diferentes formas de contestação política e social, o trabalho de Tilly foi fundamentalmente analisar sua variação e mudança: em primeiro lugar, facilitando a codificação do conhecimento existente dos historiadores sociais e políticos sobre as formas de ação coletiva popular (propondo categorias como os "eventos de protesto" que, desde um ponto de vista metodológico, acabaria se convertendo em uma importante unidade de análise no estudo das ações coletivas dentro da escola norte-americana ${ }^{7}$ ); em segundo lugar, generalizando as perguntas pelas causas das mudanças e as variações destas formas; e, em terceiro lugar, propondo a hipótese de que a história anterior da contestação limitava gravemente as opções de ação disponíveis no presente (por exemplo, a partir das conhecidas interpretações, que com inspiração em Gustave Le Bon e adeptos, ligavam os protestos ao mundo do irracional e inclusive do patológico ${ }^{8}$. Como pano de fundo dessa interpretação tillyana aparece um elemento absolutamente central que permeia sua obra, embora ganhe um caráter mais forte nos últimos anos: o caráter contingente, interativo, complexo e relacional da história e dos processos sociais.

Imbuído desse aparato interpretativo, Tilly cria em 1977 um de seus conceitos mais conhecidos: o de "repertório de contestação", introduzindo a noção de repertório no estudo da ação coletiva (Tilly, 1977). Mais adiante (1978: 143-171), o autor argumenta que embora existam diferentes formas de greves, petições e outras formas de articular demandas e reivindicações, o repertório de ações coletivas disponíveis para a população é bastante limitado. Existiriam, segundo o autor, três formas de repertórios: competitivos (para expressar rivalidades dentro de um sistema constituído), reativos (para defender direitos ameaçados) e pró-ativos (para reivindicar "novos direitos"). Mas como o próprio Tilly reconheceria duas décadas depois em uma revisão desta tríade conceitual (Tilly, 2002), o tom teleológico do trio acabou incomodando-o, em particular quando outros autores o adotaram como um esquema evolutivo. Em uma revisão desta noção, Tilly conclui que as diferentes formas não eram excludentes e que na continuidade que implicavam havia muito mais que uma mera alusão à teoria da modernização. A noção de repertório acabou se consolidando dentro das teorias das ações coletivas, sendo utilizada para observar a evidência de que a produção de demandas se concentra em uma quantidade limitada de formas, que se repetem com variações mínimas e constituem a coleção (ou repertório) dentro das quais os potenciais atores selecionam de maneira mais ou menos deliberada. Apesar desse entendimento de repertórios limitados, a crítica ao tom teleológico da noção é injusta, pois Tilly deixa claro, desde suas primeiras considerações, que os repertórios também são contingentes, pois ocorrem variações dependendo da rigidez ou flexibilidade do repertório, da inovação dos grupos e de seu uso em determinados e lugares e momentos históricos. É assim 
que o autor explica, por exemplo, como pode variar um mesmo repertório no tempo (caso da greve) e como outros podem desaparecer ou transformar-se em residuais (caso de ações como o sequestro ou a destruição de máquinas).

De fato, seria no seu clássico From mobilization to revolution que Tilly (1978) assentaria as bases de um consenso mais amplo dentro do estudo das ações coletivas nos Estados Unidos, com notável influência em outras partes do globo: introduz e elabora variáveis fundamentais como o "interesse" para a mobilização e as "oportunidades" para a produção de ações coletivas (de repressão à facilitação, de maiores oportunidades a diferentes tipos de ameaças), assim como outros três importantes componentes para o estudo da ação coletiva: a “organização", a "mobilização" e a "ação coletiva" per se que, de acordo com Tilly, poderia ser entendida a partir de três circuitos principais: pelas mudanças no repertório de ação coletiva; de várias formas de violência coletiva; e dentro das turbulências de revoluções e rebeliões. Apesar de questionável por certa rigidez, o marco teórico de Tilly era brilhante e inovador. Dialogando com autores clássicos da sociologia, de Marx a Weber, de Durkheim a Mill, Tilly consegue com este livro romper velhos consensos (crítica às teorias da modernização), distanciando-se da metodologia evolucionista e interpretativa prévia e abrindo muitos horizontes para alguns consensos e novas controvérsias sobre as relações entre a mudança social e as mudanças na mobilização coletiva. Mas talvez o maior mérito desta obra não tenha sido outro senão conseguir que o estudo da ação coletiva ganhasse um foco próprio tanto dentro da história como da sociologia, abrindo o caminho para muitos trabalhos posteriores que se enquadrariam dentro de um campo de estudo mais delimitado sobre as ações coletivas e os movimentos sociais.

Outra contribuição desta fecunda etapa de Tilly foram seus estudos sobre as diversas formas de ação coletiva e mudança social em uma perspectiva de longue durée, de inspiração braudeliana, que lhe permitiu, através de perspectivas comparadas, analisar as mudanças dos repertórios ao longo de vários séculos. O estudo das ações coletivas ganhava uma moldura de processos amplos (como a proletarização, a urbanização e a formação do Estado) e estudos comparados (principalmente entre países como a França e o Reino Unido, no caso da formação do Estado). Nesta linha, Tilly vê a mudança social não como um processo social, mas como um termo que engloba processos muito diferentes entre si e com conexões variadas (Aguilar, 2009). E assim Tilly inova, uma vez mais, tanto em termos teóricos como metodológicos deconstruindo consensos (para ele, "postulados perniciosos") do pensamento social do século XIX que teriam afetado as teorias sociais do século XX (a partir de dicotomias como a ordem e a desordem, a diferenciação e a integração) e buscando redirecionar os estudos à construção de análises concretas (no que se refere a pessoas, tempos e lugares) e históricas (para delimitar os sucessos a um período determinado). Mas além da análise de grandes estruturas, processos amplos e comparações 
enormes, cujo máximo manifesto encontra-se em Tilly (1984), o autor sempre se guiou por perguntas, hipóteses e pontos de partida gigantescos. Ainda que muitos deles tenham repercussões problemáticas, como discutiremos mais adiante, ressoam em toda a sua obra posterior: que processos fundamentais, a grande escala, devemos distinguir para poder compreender o modo em que mudou e que continua mudando o mundo? De que forma estão relacionados entre si? Com que estruturas sociais contam? Poderia uma comparação sistemática em grande escala ajudar a compreender as estruturas e os processos implicados?

Estas perguntas levaram Tilly a realizar lúcidos e complexos estudos, para alguns críticos muitas vezes rápidos e deslizantes. Seus estudos impactariam de forma considerável na produção teórica norte-americana, tanto nas teorias de mobilização de recursos, amplamente difundidas durante os anos 1970 e boa parte da década de 1980 (onde se destacam, entre outros, os trabalhos de McCarthy \& Zald, 1973 e Obserschall, 1973), como nas teorias de mobilização política ou do processo político, dominantes durante a década de 1990 (cuja máxima expressão é o já clássico Power in movement, de Sidney Tarrow, de 1998, recentemente traduzido ao português). De qualquer forma, embora vários intérpretes tenham buscado incluir o trabalho de Tilly em uma ou outra escola, coincidimos com a interpretação de Gohn (2008: 31) de que a peculiaridade de sua obra lhe atribui características próprias e um estilo de abordagem único. De fato, a questão central não é enquadrar a obra do autor em uma ou outra corrente, mas justamente o contrário, a saber, estar apto a observar sua capacidade de penetração nas diferentes matrizes teórico-metodológicas, sem que isto leve ao surgimento de etiquetas rígidas. Isto se manifestou no fecundo diálogo com outros colegas, abrindo as portas para a emergência de importantes "contribuições mistas" como a de "ciclos de protesto", noção desenvolvida plenamente por Tarrow $(1985,1998)$ a partir de insights de Tilly, para se referir a uma fase de intensificação dos conflitos e da confrontação no sistema social, que inclui uma rápida difusão da ação coletiva dos setores mais mobilizados aos menos mobilizados, um ritmo de inovação acelerado nas formas de confronto, marcos novos ou renovados para a ação coletiva, uma combinação de participação organizada e não organizada e sequências de interação intensificada entre dissidentes e autoridades (Tarrow, 1998: 144-150). Contudo, para além desses primeiros diálogos, o caráter coletivo da trajetória de Tilly - que já havia sido iniciado a partir dos seminários que impulsiona primeiro em Michigan, depois em Columbia e na New School for Social Research de Nova York - ganharia maior notoriedade a partir de meados da década de 1990, a partir de um ambicioso projeto de pesquisa denominado Contentious politics, ${ }^{9}$ que vem buscando renovar o estudo das ações coletivas. 


\section{CONTRA TILLY: CRíticAS, AUTOCRíticAS E A BUSCA DE UMA NOVA AGENDA DE PESQUISA}

O projeto Contentious politics (CP) é uma mostra clara do afã tillyano por aprender, compartilhar, arriscar e revisitar suas próprias contribuições, que nunca estiveram isentas de polêmicas, críticas e autocríticas. Poder-se-ia dizer que foram três as principais críticas realizadas à primeira etapa da obra de Tilly e suas implicações no estudo das ações coletivas: a primeira, de caráter ontológico (o viés estruturalista), a segunda, de cunho teórico (o enfoque institucionalista) e a terceira, mais metodológica (os limites da amplitude comparativa).

A primeira crítica está relacionada ao que estudamos, ou seja, ao próprio objeto de estudo. Trata-se de uma polêmica questão que nas ciências sociais se refere à ênfase nos padrões e estruturas sociais ou na ação social. No estudo das ações coletivas e dos movimentos sociais, como em muitos outros campos, a questão foi colocada quase sempre como uma disjuntiva que separou os "estruturalistas" dos "movimentalistas" (ou "acionalistas", no sentido de Touraine) cujos objetivos estão mais orientados ao ator/ação e ao âmbito das subjetividades. Isto foi levando à construção de uma dicotomia rígida, na qual a obra de Tilly, assim como as teorias da mobilização de recursos, tem sido habitualmente localizada no primeiro grupo, já que buscam demonstrar que os movimentos sociais não podem ser entendidos sem sua configuração estrutural e suas relações com o "processo político". Como reconhece, a modo de balanço, Mayer Zald, um dos máximos expoentes das teorias de mobilização de recursos,

nossas teorias foram úteis porque criaram um espaço para perspectivas renovadas de estudo, problematizando certas questões e desenvolvendo de forma mais sofisticada análises da psicologia social e da macrossociologia dos movimentos sociais [...], porém tornaram-se velhas, não dedicando atenção suficiente a uma série de questões como a relação entre classe e formação de identidade para a mobilização, as oportunidades políticas, as estruturas do Estado como elementos determinantes ou restritivas para a mobilização social, os outcomes, os microfundamentos dessas dinâmicas, o papel dos efeitos dos protestos e a intersecção entre crise cultural e atividade dos movimentos sociais (Zald, 1992: 327).

A crítica ao viés estruturalista é pertinente, mormente no estudo dos movimentos sociais, porém tem seus limites. Melucci (1989b, 1992, 1996) é o autor que melhor assinala o principal desses limites, a partir da necessidade de superar o debate em termos binários, ainda que não tenha sido recuperado em profundidade por "ex-estruturalistas" reconhecidos como Tarrow (2003), que tentam ativar um "giro relacional" (relational shift) aos seus estudos. O elemento-chave na proposta do italiano, importante de recuperar nesse momento, é a identidade coletiva como fator intermediário, na qual as estruturas podem condicionar, porém não determinar a ação que pode acontecer ou não, dependendo dos recursos materiais e simbólicos, da capacidade de mobilização 
e, em particular, da existência de redes de confiança e de uma identidade coletiva. Isto supõe um importante avanço frente o individualismo metodológico prévio, típico das teorias da mobilização de recursos e da eleição racional, mas também frente àquelas interpretações que se centram fundamentalmente no caráter determinante do contexto e suas oportunidades e/ou restrições para a ação, como é o caso das leituras mais rígidas das estruturas de oportunidades políticas. Assim sendo, estamos de acordo com Melucci de que no estudo dos movimentos sociais a ação em si já é um relevante objeto de pesquisa, ainda que isto não signifique descartar totalmente qualquer tipo de análise de estrutura. A crítica ao estruturalismo e à necessidade de passar de um modelo estático-estrutural a relatos mais dinâmicos foi (continua sendo) uma das mais fortes dentro do estudo dos movimentos sociais, porém não se tratou somente de uma crítica externa, senão que teve uma forte repercussão dentro das aproximações norte-americanas, onde esta posição ontológica sempre foi privilegiada. Tilly contribuiu para essa autocrítica e, de fato, sempre buscou, nas interações e nas relações sociais as chaves de interpretação do que podemos considerar um "estruturalismo relacional". Nos debates norte-americanos críticos, Jeff Goodwin \& James Jasper (1999) escreveram uma árdua e difundida denúncia do viés estruturalista e caráter tautológico, trivial e inadequado de alguns usos das teses de oportunidades políticas e dos modelos de processo político que ao insistir em metáforas estruturais, dificultam a explicação de como as oportunidades políticas afetam as ações dos movimentos. Propõem uma visão mais laxa das oportunidades políticas, e certamente mais rica em termos analíticos, que tenha cuidado com a elasticidade conceitual, reconheça que o cultural e os processos estratégicos definem e criam os fatores usualmente descritos como "estruturais".

A segunda crítica tem uma íntima relação com a primeira e também é consistente, já que Tilly sempre deu grande importância às respostas e posições de governos, competidores e elites e suas posições e interações frente à ação coletiva e os movimentos sociais, os processos de formação do Estado, a produção e restrição de oportunidades políticas e os efeitos democratizantes. Junto a vários outros autores norte-americanos que se alinham às teorias do processo político, consolidaram toda uma linha de pesquisa em que os movimentos sociais são analisados fundamentalmente em função de suas relações com o Estado e o sistema político. Para Gohn (2006: 113), trata-se de uma abordagem construída de forma bastante estática, que não se desvincula do reducionismo e utilitarismo da discussão norte-americana prévia. Ainda assim, no que se refere aos aportes mais específicos de Tilly, importantes nuanças devem ser feitas: por um lado, o enfoque institucional não necessariamente é estático; e, por outro, se fizermos uma análise sistemática de sua obra, poucas vezes o autor reflete diretamente sobre os movimentos sociais (nos últimos anos destaca-se Tilly, 2004), sendo que seu foco sempre foi muito mais amplo, estando interessado 
na ação coletiva e na contestação política de forma mais geral. Isto leva a que o autor adote uma visão minimalista dos movimentos sociais, muitas vezes entendidos como "campanhas" ou reivindicações/demandas coletivas às autoridades.

Em terceiro lugar, a crítica referente à amplitude comparativa é uma faca de dois gumes: por um lado, nos deparamos com a impossibilidade de gerar uma causalidade sistemática a partir de comparações tão amplas, mas, por outro lado, com a vantagem de um olhar que cruza diferentes perspectivas temporais, geográficas e de ações. Exemplos ad hoc são frequentemente utilizados, dificultando ainda mais a geração de um modelo interpretativo abrangente. $\mathrm{O}$ próprio Tilly reconhece a impossibilidade de alcançar uma ordem estrutural causal no estudo das ações coletivas e dos movimentos sociais, porém considera relevante a busca de certas causas que supostamente possam contribuir para a explicação. Considero esta crítica metodológica central, embora sua construção arriscada seja fundamental para avançar no debate. Nas últimas décadas, os estudiosos dos movimentos sociais vêm optando por diferentes formas de pesquisa (aproximações quantitativas e qualitativas que utilizam ferramentas tão variadas como as entrevistas em profundidade, estudos de arquivos, observação participante, estudos de caso, histórias de vida, análise de discurso etc.) e, dentro deste amplo leque de ferramentas disponíveis, a peculiar visão de Tilly oferece, ainda que possa haver déficits, uma singular visão comparativa que permite vislumbrar a ação coletiva com uma amplitude necessária para avançar na construção de modelos complexos que complementem a mera casuística.

As três críticas mencionadas, principalmente as duas primeiras, tiveram um eco central nas controvérsias que moldaram o debate teórico sobre os movimentos sociais como objeto de estudo desde sua institucionalização acadêmica a partir da década de 1960. Estas críticas também foram determinantes para que a partir de meados da década de 1990 surgisse o projeto Contentious politics, que nasce devido ao sentimento de profunda ambivalência compartilhada por esses autores sobre a proliferação dos estudos sobre os movimentos sociais (ver McAdam, 2001). Por um lado, alegravam-se de como um objeto de estudo que durante muito tempo havia sido periférico converteu-se em um tema com grande legitimidade dentro de boa parte do meio acadêmico. Por outro lado, compartilhavam uma sensação de crescente isolamento e desconexão vis-à-vis outros campos de estudo afins, tais como o das revoluções, os nacionalismos e a democratização. Com o objetivo de juntar acadêmicos desses diferentes campos para explorar algumas possibilidades de síntese teórica organiza-se, em 1995, um seminário com o título genérico Contentious politics. Seria somente o início de um amplo diálogo cruzado que continua vigente, apesar da morte de Tilly. As primeiras impressões e resultados são publicados em um texto no primeiro número da hoje conhecida revista Mobilization, na qual os impulsores do projeto propõem que diferentes formas de confronto político como os movimentos sociais, revoluções, mobilizações étnicas e ciclos de protestos compartilham 
algumas propriedades causais, porém estas similaridades seriam obscurecidas pela fragmentação disciplinar (McAdam, Tarrow \& Tilly, 1996). Ainda assim, propõem desenvolver esta nova agenda de pesquisa a partir de quatro linhas principais: movimentos sociais, ciclos e revoluções; identidades coletivas e redes sociais; movimentos sociais e instituições políticas; globalização e contestação transnacional.

As reações chegaram rapidamente. No volume seguinte da revista Mobilization, Lichbach (1997) critica a possibilidade de uma grande síntese teórica neste novo e amplo campo de estudo devido à persistência das tensões entre a perspectiva das teorias da escolha racional e as teorias das oportunidades políticas. A réplica mais contundente do projeto CP viria em 2001, com a publicação de Dynamics of contention, no qual o confronto político é definido como "interações coletivas, episódicas e públicas entre os responsáveis das demandas e seus objetos quando: a) ao menos um governo é demandante, objeto de demandas ou parte das demandas e, b) as demandas, caso se concretizem, afetam aos interesses de, ao menos, um dos demandantes" (McAdam, Tarrow \& Tilly, 2001: 5). Em suma, com esta amplíssima definição os autores buscam abranger qualquer luta política coletiva com o objetivo de compor um marco que permita a comparação de processos e mecanismos causais similares que se repetem dentro de uma grande variedade de lutas, mas que produzem diferentes resultados agregados, dependendo das condições iniciais, das combinações e as sequências em que se desenvolvem. Para isto, reconhecem explicitamente que provêm de uma tradição estruturalista e que o estudo sistemático de vários eventos de protesto, tanto na Europa como nos Estados Unidos, possibilitou que entrevissem a necessidade de levar em conta as interações estratégicas e a cultura (ver Tarrow, 2012). A consequência direta deste diagnóstico é a inclusão das redes e da comunicação interpessoal (Tilly, 2005) e várias formas de negociações contínuas (incluída a identitária) como elementos centrais no estudo das dinâmicas de contestação, embora muitas vezes estas somente apareçam de forma residual.

É fundamental observar que na delimitação deste novo projeto de pesquisa os movimentos sociais, assim como na obra anterior de Tilly, são somente uma parte do objeto de estudo, já que o horizonte é a análise mais ampla da ação coletiva contestatória ou do confronto político em suas diferentes manifestações. Assim, os autores do projeto CP propõem diferenciar entre mecanismos (uma classe de eventos que alteram as relações entre conjuntos específicos de elementos, de forma idêntica ou muito similar, sobre uma variedade de situações), processos (sequências regulares desses mecanismos que produzem transformações similares - normalmente mais complexas e contingentes - destes elementos) e episódios (correntes contínuas de confronto que incluem demandas coletivas relacionadas aos interesses das outras partes). Deste modo, a lógica proposta passa por: a) identificar episódios ou séries de episódios contestatórios 
com certos rasgos problemáticos; b) localizar os processos que, dentro desses episódios, constituem ou produzem a característica problemática; c) procurar os mecanismos causais cruciais dentro desses processos. E como essa proposta é desenvolvida em termos empíricos? Os autores selecionam episódios muito variados (tanto em termos temporais, como geográficos e de formas de confronto), tais como a revolução sandinista na Nicarágua, a descomposição soviética ou a revolução francesa de 1789, e logo utilizam uma estratégia comparativa complexa que possibilita o cruzamento dos diferentes casos de contestação a partir da busca causal de processos e mecanismos.

Ainda que o projeto suponha um novo ponto de inflexão no estudo das ações coletivas, há uma dificuldade para estabelecer sequências lógicas e claras de concatenação entre os mecanismos e processos que passam a ocupar o lugar de uma série de variáveis presentes na agenda clássica do estudo dos movimentos sociais que eles mesmos ajudaram a consolidar desde os anos 1960, tais como: oportunidades, ameaças, estruturas de mobilização, repertórios e marcos (ver crítica de Ibarra \& Martí, 2005). Além disso, mantendo a constante autocrítica os próprios membros do projeto CP também editariam um livro coletivo titulado Silêncios e vozes no estudo do confronto político (Aminzade et al., 2001) que busca discutir alguns temas descuidados e/ou silenciados no estudo do confronto político. ${ }^{10}$ Tilly apostaria a partir desse momento por incorporar alguns desses temas silenciados - em particular a discussão sobre a importância do espaço e a contestação performática (Tilly, 2008) - e por desenvolver de forma mais sistemática alguns dos elementos do projeto - principalmente o estudo da democratização (Tilly, 2007) como processo dinâmico relacionado ao confronto político. Discutirei na próxima seção esses e outros silêncios fundamentais para a construção de uma agenda renovada no estudo das ações coletivas e dos movimentos sociais.

\section{PARA ALÉM DE TILLY:}

\section{ABERTURAS, DESDOBRAMENTOS E NOVOS HORIZONTES}

Sem o objetivo de fazer um repasso exaustivo à trajetória de Tilly, algo difícil devido à peculiaridade e vasto alcance de sua obra, buscou-se até aqui mapear de forma breve algumas de suas principais contribuições teórico-metodológicas para o estudo das ações coletivas, assim como narrar aquelas críticas e polêmicas que levaram a autor a buscar, de forma individual ou coletiva, durante as últimas duas décadas, relatos mais dinâmicos e relacionais. Finalmente, a modo de conclusão, recuperaremos alguns debates com os quais Tilly dialogou - de forma direta ou indireta - ou chegou a criticar em algum momento, e que constituem, do nosso ponto de vista, desafios centrais para repensar a análise da ação coletiva e dos movimentos sociais contemporâneos. ${ }^{11}$ 
O primeiro desafio refere-se à necessidade de espacializar as ações coletivas e os movimentos sociais. A obra de Tilly supõe uma tentativa de abordar os diferentes processos através de uma análise de longo prazo, onde a sociologia se encontra com a história de maneira forte, mas fragmentada. Tanto nas suas análises, como de forma mais ampla na teoria da mobilização dos recursos e principalmente nas teorias do processo político, os "eventos de protesto" se convertem em marco temporal de referência, os "ciclos de protesto" em ferramentas para analisar períodos de alta mobilização social e as "oportunidades políticas" são entendidas frequentemente como oportunidades históricas (Miller, 2000). No entanto, esta hegemonia do tempo provocou uma incapacidade das teorias das ações coletivas ocidentais em interpretar, de forma conciliada, os "espaços de protesto", a dimensão geográfica inerente aos ciclos e a maior ou menor abertura de oportunidades políticas de acordo com os diferentes lugares.

O espaço é, salvo raras exceções, visto como um mero contexto onde ocorrem as interações sociais, como um pano de fundo não problematizado e não como uma construção social (Lefebvre, 1974), que se reconstrói no tempo através da interação de diferentes atores e escalas (do local ao global, passando por vários níveis intermédios). Assim como para Tilly a história e o tempo não são meros contextos, o lugar e o espaço devem ser entendidos como esferas de luta e elementos definidores do movimento social. Nos últimos anos, esse esforço analítico transcende o trabalho dos geógrafos e se insere em um spatial shift mais amplo nas ciências sociais e humanas, informando parte do debate pós-estruturalista e pós-moderno, e pressionando a reconsideração da importância do espaço dentro da teoria social (Soja, 1989; Harvey, 1989). Indagado sobre este déficit, Charles Tilly ensaiou algumas respostas, assumindo a necessidade de repensar o papel do espaço nos estudos sobre o confronto político (Tilly, 2000), ao mesmo tempo em que repreende os geógrafos pelo fato de não integrarem suficientemente em suas análises sobre movimentos sociais os aportes do programa CP (Tilly, 2003). De fato, o diálogo interdisciplinar real e fértil, se produz poucas vezes e é fundamental, como veremos adiante, para uma reconstrução da agenda de estudo das ações coletivas e dos movimentos sociais. Só isto permitirá caminhar empiricamente na direção de um projeto de espacializar as ações coletivas, que deve ser filosoficamente substantivo e politicamente crítico, conjugando o tempo e a história com o espaço. Com esse horizonte, poder-se-á projetar uma consciência espacial nos estudos históricos e examinar criticamente as relações de poder e seus vínculos com os lugares (Elden, 2001). Isto é central para interpretar muitos movimentos sociais latino-americanos, fortemente territorializados e com lutas e disputas por terra, territórios e territorialidades. No entanto, longe somente de uma visão territorial do lugar (cujo cúmulo de reflexões e estudos já é importante), proponho que estejamos dispostos também a levar a sério uma visão relacional do lugar, central para analisar, de forma espacializada, as relações entre os diferentes territó- 
rios, mediadas por redes, escalas e dinâmicas de difusão, típicas do ativismo contemporâneo (Bringel, 2011c).

Isto nos leva a um segundo desafio inter-relacionado: a necessidade de uma abertura disciplinar no estudo das ações coletivas e dos movimentos sociais. A progressiva institucionalização do estudo dos movimentos sociais e da ação coletiva a partir da década de 1960 se produziu através de uma marcada hegemonia de determinadas disciplinas, principalmente a sociologia, em diálogo com a ciência política, a história, a antropologia e a psicologia social. Foi se construindo um campo comum de discussão para os estudiosos do tema que contribuiu a decifrar várias perguntas como: por que as pessoas participam dos movimentos sociais? Como estão estruturados? Por que a participação aumenta em alguns casos, enquanto em outros diminui? Como interagem os movimentos sociais com outros atores sociais e políticos? Contudo, novas perguntas foram surgindo devido às importantes mudanças que aparecem a partir de inícios da década de 1990: a emergência de novos repertórios de ação coletiva, a ampliação e interação das múltiplas escalas de atuação, a maior atenção analítica em zonas geográficas não-ocidentais, a utilização de internet e outras ferramentas tecnológicas como os telefones celulares, entre outros elementos.

A resposta a estas perguntas exige uma imperiosa e complexa abertura disciplinar em que disciplinas como a geografia e as relações internacionais têm muito que contribuir. No primeiro caso, para captar, conforme mencionado anteriormente, as múltiplas espacialidades da ação coletiva e dos movimentos sociais para interpretar com maior profundidade as relações entre protesto, natureza e território, bem como as práticas espaciais dos movimentos. No segundo, para aprofundar no estudo da dimensão internacional e transnacional da ação coletiva. Mais que isso: um enfoque integrador entre as perspectivas críticas da geografia e das relações internacionais permite uma resistência a um puro estadocentrismo e a articulação de alternativas para aquém e para além desse âmbito, considerando o sentido global do lugar (Bringel \& Echart, 2008; Santos, 2002; Massey, 2005) e a superação de um nacionalismo metodológico, todavia imperante, inclusive quando o ativismo transnacional passa a ser o foco central da análise. Neste ponto, é importante ir além das posições hegemônicas do debate norte-americano (nucleado pelo clássico de Keck \& Sikkink, 1998), onde a dimensão internacional aparece amiúde de forma instrumental para "movimentos sociais" que têm suas estruturas de oportunidades políticas "fechadas" no âmbito doméstico, ou bem como uma escala relativamente rígida, onde dificilmente podemos traçar interações de escalas ou identificar atores cuja base de socialização não seja, prioritariamente, a nacional, como em alguns casos dos ativistas antiglobalização. Trabalhos como o de Von Bulow (2011) têm lançado novas pistas para o debate, mas ainda há um longo caminho por percorrer para demonstrar que as "oportunidades políticas" não "saltam escalas" no vazio ou de forma teleológica (do local ao global, sempre nessa ordem) e, 
por isso, torna-se central analisar tanto a construção social das ações coletivas transnacionais como as complexas geografias de suas interações.

O terceiro desafio supõe uma abertura ainda mais ampla, de caráter epistemológico, sobre como conhecemos as coisas. Os períodos de grandes convulsões são momentos em que normalmente emergem questionamentos profundos. Foi assim na primeira grande crise sistêmica do século XX, que precedeu a atual crise global, quando no contexto da "grande depressão" de 1929 surgiu um importante debate epistemológico que passa a questionar as bases tradicionais da ciência e seu modelo indutivo e positivista (Popper, 1934). Não é possível determinar ainda com precisão as consequências das turbulências globais atuais, mas trata-se de um período de transição não somente paradigmática como também societária (Santos, 2005), que pode levar a rupturas maiores no terreno científico, ainda que estas sejam, por ora, difíceis de visualizar. Até o momento, nas ciências sociais, faz-se notar o crescente questionamento do caráter patriarcal, racista e eurocêntrico da modernidade e suas formas de conhecimento, o que, consequentemente, permite vislumbrar a tentativa de construção de epistemologias alternativas (Bringel, 2011b). Contudo, devemos ser cautelosos. No campo de estudo das ações coletivas e dos movimentos sociais, isto não deve supor o abandono total de todas as teorias e ricas categorias prévias (sobretudo aquelas de caráter mais intermediário, como as propostas por Tilly), nem um "giro pós-colonial" cego, mas sim sua atualização crítica a partir de uma maior pluralização dos atores e centros que produzem conhecimento sobre os movimentos sociais, assim como a exploração de novos caminhos e interações da teoria crítica com as contestações sociais para além do ocidentocentrismo imperante (Bringel \& Domingues, 2012).

A interação do mundo militante com o mundo acadêmico na produção de conhecimento certamente não é um tema novo e no seio deste debate reside a clássica tensão entre aqueles que consideram que existe uma explicação científica possível sobre a vida política (entre os que se encontram os partidários das "teorias da escolha racional", cuja proposição olsiana afetou em grande medida o início dos debates sobre os movimentos sociais) e aqueles que, como nós, negamos esta possibilidade (construindo e reconstruindo, desde diferentes perspectivas, um amplo leque de motivações humanas). Nesta última linha, a ruptura principal consiste em atualizar as contribuições metodológicas e posturas epistemológicas de autores como Orlando Fals-Borba (1961, 1979), Rodolfo Stavenhagen (1971) e outros colegas latino-americanos que marcaram um ponto de inflexão já nos anos 1960, tanto nas formas de construir como de difundir o conhecimento científico de suas pesquisas, criando as bases para o que posteriormente seria conhecido como "pesquisa-ação-participativa".

A atualização crítica do legado desses e outros autores/debates passa, na atualidade, em primeiro lugar, por desconstruir os discursos hegemônicos (muito difundidos, por certo, nos círculos "latino-americanistas" da Europa e dos 
Estados Unidos) de que isso foram "águas passadas" de uma América Latina dos anos 1960 e 1970 que padecia uma "sobreideologização dos cientistas sociais". Trata-se de uma crítica parcial de grupos que na atualidade não questionam a privatização da educação nem a "sobrevalorização do quantitativo" e certa tecnificação da atividade intelectual. A especialização do saber e a profissionalização das ciências sociais na região nas últimas décadas foram positivas e contribuiu para o desenvolvimento do campo acadêmico, mas também contribuiu para um distanciamento entre o saber acadêmico e o compromisso militante (Svampa, 2008: 25). Isto vem sendo questionado de forma incipiente na última década, a partir da emergência de vários movimentos sociais mais autorreflexivos sobre suas próprias práticas, e que reivindicam um diálogo de saberes e a criação de espaços mistos (acadêmico-militantes) de reflexão. Em várias de suas dimensões, os movimentos sociais são como icebergs, com grande parte da sua vida acontecendo por debaixo da superfície visível (Clemens \& Hugges, 2002: 212). Captar essas dimensões invisíveis para um "analista de escritório" (que normalmente tem como foco somente os aspectos visíveis da ação coletiva, ou seja, sua dimensão exógena) é fundamental. Porém, também é importante ir além do modelo de "interação dentro da objetividade" de modelos como a "intervenção sociológica" (Touraine, 1978, 1982), para assumir que é possível e necessário conciliar o compromisso militante e a análise da vida social, sempre que a opção seja uma proximidade, empatia e trabalho com os movimentos sociais que não suponha uma cegueira analítica que se limite a reproduzir a voz dos atores sociais em vez de produzir conhecimento crítico.

Se cruzarmos os três desafios mencionados, possivelmente consigamos respostas mais completas e complexas para interpretar a ação coletiva e as práticas dos movimentos sociais. Neste sentido, a abertura epistemológica, disciplinar e a inserção de uma sensibilidade espacial podem contribuir a buscar respostas a outros desafios teóricos contemporâneos, tais como: de que maneira pensar a dimensão internacional e transnacional da ação coletiva? Contribuem essas aberturas e o enfoque espacial para superar o nacionalismo metodológico? Como analisar a democracia e a democratização, em sua relação com os movimentos sociais, para além do Estado territorial? Como construir interpretações teóricas sobre os movimentos atuais, sem negligenciar a importância do corpus produzido pelas teorias dos movimentos sociais há mais de cinquenta anos, mas ao mesmo tempo desvinculando-se do eurocentrismo e de modelos estático-estruturais? Quais são as referências de interpretação e transformação da realidade que emergem das práticas e discursos dos atores/sujeitos sociais contemporâneos? E finalmente, outra indagação, de corte conceitual, que me parece ainda mais decisiva: quais são os novos sentidos e significados que vêm sendo dados hoje às noções de "militância", "mobilização", "engajamento", "ativismo" e "movimento social"? Não é possível responder aqui a essas amplas perguntas, já que todas elas exigem um grande esforço de 
reinterpretação e atualização das teorias das ações coletivas e dos movimentos sociais a ser desenvolvido em trabalhos futuros. De qualquer forma, seja qual for o caminho escolhido na busca de respostas a estas e outras questões relacionadas, Tilly pode (e deve) ser tomado como uma referência iniludível, tanto por seus importantes aportes ao debate, brevemente assinalados neste texto, como por sua capacidade de relacionar o debate dos movimentos sociais com campos afins e reformular constantemente suas próprias ideias. Além disso, combater o ocidentocentrismo não significa negar a produção acadêmica ocidental, da qual certamente Tilly ainda terá muito que contribuir às nossas discussões, embora já não esteja entre nós.

Artigo recebido para publicação em fevereiro de 2012.

Breno Bringel é doutor em Ciência Política pela Universidade Complutense de Madri, onde atua como docente nos Programas de Pós-Graduação em Estudos Contemporâneos da América Latina, e Cooperação Internacional e Desenvolvimento. Atualmente é professor/pesquisador do Instituto de Estudos Sociais e Políticos (Iesp) da Universidade do Estado do Rio de Janeiro (Uerj), onde coordena, com José Maurício Domingues, o Núcleo de Estudos de Teoria Social

e América Latina. Nos últimos anos tem pesquisado e publicado vários textos sobre movimentos sociais, ação coletiva transnacional, espacialidade da política contestatória e internacionalismo. Sua publicação mais recente é o livro, organizado com Maria da Glória Gohn, Os movimentos sociais na era global (2012). 


\section{NOTAS}

1 Versões preliminares deste artigo foram apresentadas em dois encontros: o International Workshop Tribute to Charles Tilly, celebrado nos dias 7 e 8 de maio de 2009 em Madri; e o XIV Congresso Brasileiro de Sociologia, realizado entre os dias 28 e 31 de julho de 2009 no Rio de Janeiro. Agradeço os comentários dos colegas participantes nas mesas-redondas de ambos os eventos, assim como a Carlos R.S. Milani e Carlos A. Costa Ribeiro pelas sugestões a uma versão prévia desse texto. Sid Tarrow, por seu diálogo sobre os rumos do projeto Contentious politics, e José Maurício Domingues e demais pesquisadores do Netsal (Iesp-Uerj), pelos debates constantes, certamente enriqueceram este texto e estão isentos de qualquer responsabilidade pelos meus possíveis erros. Finalmente, gostaria de agradecer os comentários de um parecerista anônimo da revista Sociologia \& Antropologia.

2 Utilizamos como fonte para a reconstrução detalhada de sua bibliografia um CV completo elaborado por Tilly alguns meses antes de seu falecimento. A variação do número de artigos citado deve-se a que alguns deles, não incluídos neste cômputo, são versões ligeiramente modificadas do original, publicados em outros idiomas. Uma lista detalhada sobre a produção de Charles Tilly pode ser encontrada no último capítulo do livro editado por Funes (2011), uma excelente homenagem ao autor publicada em Madri quando já havíamos terminado de redigir a primeira versão esse texto.

3 Nem sequer a publicação de alguns textos do autor em Portugal (caso do livro As revoluções europeias: 1492-1992, publicado pela Editorial Presença em 1996) contribuíram para suprir esse déficit entre os países de língua portuguesa.

4 Sessões, mesas-redondas e grupos de trabalho organizados por mim e por Maria da Glória Gohn em eventos nacionais (Sociedade Brasileira de Sociologia) e internacionais (Associação Internacional de Sociologia, Associação Internacional de Ciência Política e Associação Latino-Americana de Sociologia) realizados no Brasil nos últimos anos confirmam essa tendência. Além dos dossiês mencionados, muitos outros têm insistido recentemente na renovação do debate sobre os movimentos sociais no Brasil (ver, por exemplo, 
Sociedade \& Estado, 2006, 21/1; Caderno CRH, 2008, 21/54; Ciências Sociais Unisinos, 2011,46/1), alguns deles com uma perspectiva mais tillyana (Sociologias, 2011, 13/28).

5 Em Gohn (1997) ainda encontramos uma das melhores sistematizações deste debate que dividiu as teorias dos movimentos sociais até o início da década de 1990. Ver também Neveu (1996).

6 Para um ótimo balanço do debate sobre a sociedade civil nessa década, ver Gurza Lavalle (2003).

7 Esta estratégia metodológica foi se aperfeiçoando com o tempo. No início se caracterizava pelo registro dos eventos de protesto, principalmente a partir dos meios de comunicação. Em alguns casos, Tilly também utilizava arquivos policiais e judiciários para a reconstrução histórica de protestos extralegais ou mais "rupturistas". Contudo, ambos os recursos rapidamente demonstraram seus limites, já que mostram uma versão parcial (institucional e elitista) dos protestos, além de analisar somente a parte visível das ações coletivas (o que Melucci, 1989a, denominaria posteriormente como "a miopia do visível", ou seja, um enfoque se concentra exclusivamente nos aspectos mensuráveis da ação coletiva). Esses limites levaram a que Tilly e vários autores vinculados à escola norte-americana incorporassem muitas outras variáveis para a reconstrução histórica das ações coletivas, tais como a análise de documentação de organizações, os marcos interpretativos ou os resultados das mobilizações. Para aprofundar neste debate ver Clemens \& Hughes (2002).

8 De forma similar à forte influência de Le Bon no caso norte- americano, também houve na América Latina, no início do século XX, uma vasta literatura que relacionava a sociedade e as "massas" ao patológico, ainda que, neste caso, não se estabelecia uma relação tão direta com as motivações das mobilizações sociais, mas à própria população excluída e à mestiçagem de forma mais geral. Ver, por exemplo, os textos dos argentinos Álvarez (1899) e do boliviano Arguedas (1909), cujos títulos, Manual de patologia política e Pueblo enfermo, respectivamente, são bastante ilustrativos.

9 Aproveito para fazer um importante parêntese terminológico. As traduções mais habituais do termo "contentious 
politics" tem sido "política contenciosa", "litígio coletivo" e mais recentemente "confronto político". Em espanhol, o termo tem sido traduzido como "política contenciosa" ou como "contienda política". Cremos que a tradução mais satisfatória seria a de "confronto político" ou inclusive "política contestatória", assim como termos contend/contention como "contestar ou confrontar" / "contestação ou confronto", já que, em nossa opinião, estas acepções preservam melhor o sentido de oposição, conflito e reivindicação intrínseco a este projeto coletivo de pesquisa, em detrimento do sentido mais jurídico de "política contenciosa" (que poderia resultar confuso) ou do sentido demasiado generalista de "litígio coletivo" ou "contenda política" (como disputa entre vários).

10 Ver também, a modo de nova autocrítica, o número especial da revista Mobilization, publicado em 2011, dez anos após a aparição de Dynamics of contention.

11 Entre os estudiosos dos movimentos sociais parece haver uma sensação compartilhada de que nos encontramos realmente em um momento de muitos desafios teóricos (e políticos). São várias as tentativas recentes de sistematizar algumas destas novas orientações e caminhos. No caso latino-americano, destaca-se, entre outros, os trabalhos recentes de Bringel \& Gohn (2012), Bringel \& Domingues (2012), Falero (2012), Gohn (2008), Seoane, Taddei \& Algranati (2006), Svampa (2010).

\section{REFERÊNCIAS BIBLIOGRÁFICAS}

Aguilar, Salvador. In memoriam. Las relaciones constituyen las unidades sociales básicas: en la muerte de Charles Tilly. Revista Internacional de Sociología, 2009, 67/1, p. 213-218.

Alonso, Ângela \& Araújo, Nadya. Entrevista com Charles Tilly. Tempo Social, 2004, 16/2, p. 289-297.

Álvarez, Agustín. Manual de patología política. Buenos Aires: La Cultura Argentina, [1916] 1989.

Aminzade, Ronald et al. Silence and voice in the study of contentious politics. Cambridge: Cambridge University Press, 2001. 
Arguedas, Alcides. Pueblo enfermo: contribuciones a la psicología de los pueblos hispano-americanos. Santiago: Ercilla, [1909] 1937.

Bringel, Breno. A busca de uma nova agenda de pesquisa sobre os movimentos sociais e o confronto político: diálogos com Sidney Tarrow. Política \& Sociedade, 2011a, 10/18, p. 51-73.

Ativismo transnacional, o estudo dos movimentos sociais e as novas geografias pós-coloniais. Estudos de Sociologia, 2011b, 16/2, p. 185-215.

El estudio de los movimientos sociales en América Latina: reflexiones sobre el debate postcolonial y las nuevas geografías del activismo transnacional. In: Acosta, Yamandú et al. (orgs.). Pensamiento crítico y sujetos colectivos en América Latina: perspectivas interdisciplinarias. Montevidéu: Trilce/ Udelar, 2011c, p. 39-59.

\& Domingues, José Maurício. Teoria crítica e movimentos sociais: intersecções, impasses e alternativas. In: Bringel, Breno \& Gohn, Maria da Glória (orgs.). Movimentos sociais na era global. Petrópolis: Vozes, 2012.

Bringel, Breno \& Echart, Enara. 10 anos de Seattle, o movimento antiglobalização e a ação coletiva transnacional. Ciências Sociais Unisinos, 2010, 46/1, p. 28-36.

Crisis globales y luchas transnacionales. In: Ibarra, Pedro \& Grau, Elena (orgs.). Crisis y respuestas en la red: anuario de movimientos sociales 2009. Barcelona: Icaria, 2009, p. 210-220.

Movimentos sociais e democracia: os dois lados das

fronteiras. Caderno CRH, 2008, 21/54, p. 457-475.

Bringel, Breno \& Gohn, Maria da Glória (orgs.). Movimentos sociais na era global. Petrópolis: Vozes, 2012.

Bruckman, Mônica \& Santos, Theotônio dos. Os movimentos sociais na América Latina: um balanço histórico. In: Santos, Theotônio dos (org.). Países emergentes e os novos caminhos da modernidade. Brasília: Unesco, 2008, p. 181-202.

Clemen, Elisabeth \& Hughes, Martin. Recovering past protest: historical research on social movements. In: Klandermans, Bert \& Staggenborg, Suzanne (orgs.). Methods of social movement research. Minneapolis: University of Minnesota Press, 2002, p. 201-230. 
Falero, Alfredo. Entre o rigor teórico-metodológico e a criatividade: algumas chaves cognitivas para a pesquisa dos movimentos sociais na América Latina. In: Bringel, Breno \& Gohn, Maria da Glória (orgs.). Movimentos sociais na era global. Petrópolis: Vozes, 2012.

Fals-Borba, Orlando. Campesinos de los Andes: estudio sociológico de Saucío. Bogotá: Universidad Nacional, 1961.

El problema de cómo investigar la realidad para transformarla. Bogotá: Tercer Mundo, 1979.

Franzé, Javier. De qué pensamiento y de qué política se habla cuando hablamos de historia del pensamiento político? Algunos problemas pedagógicos y metodológicos en torno a la historia del pensamiento político como disciplina. In: Cairo, Heriberto \& De Sierra, Gerónimo (orgs.). América Latina, una y diversa: teorías y métodos para su análisis. San José: Alma Mater, 2008, p. 271-287.

Funes, José Maria (org.). A propósito de Tilly: conflicto, poder y acción colectiva. Madri: CIS, 2011.

Gohn, Maria da Glória. Teorias dos movimentos sociais: paradigmas clássicos e contemporâneos. São Paulo: Loyola, [1997] 2006 .

Novas teorias dos movimentos sociais. São Paulo: Loyola, 2008.

Goodwin, Jeff \& Jasper, James. Caught in a winding, snarling wine: the structural bias of political process theory. Sociological Forum,1999, 14/1, p. 27-54.

Gurza Lavalle, Adrian. Sem pena nem glória: o debate sobre a sociedade civil nos anos 1990. Novos Estudos Cebrap, 2003, 66, p. 91-109.

Harvey, David. The condition of postmodernity: an enquiry into the origins of cultural change. Oxford: Blackwell, 1989.

Ibarra, Pedro \& Martí, Salvador. Prólogo a la edición castellana. In: McAdam, Doug; Tarrow, Sidney \& Tilly, Charles. Dinámica de la contienda política. Barcelona: Hacer, 1999.

Lefebvre, Henri. Production de l'espace. Paris: Anthropos, 1974. Lichbach, Mark. Response to McAdam, Tarrow and Tilly: contentious maps of contentious politics. Mobilization: An International Quarterly, 1997, 2/1, p. 87-98. 
Massey, Doreen. For Space. Londres: Sage, 2005.

McAdam, Doug. Preface. In: Aminzade, Ronald et al. Silence and voice in the study of contentious politics. Cambridge: Cambridge University Press, 2001.

; Tarrow, Sidney \& Tilly, Charles. To map contentious politics. Mobilization: An International Quarterly, 1996, 1/1, p. 17-34.

. Dynamics of contention. Cambridge: Cambridge University Press, 2001.

McCarthy, John \& Zald, Mayer. The trend of social movements in America. Morristown, NJ: General Learning Press, 1973.

Melucci, Alberto. Um objetivo para os movimentos sociais? Lua Nova: Revista de Cultura e Política, 1989a, 17, p. 49-66.

Nomads of the present: social movements and individual needs in contemporary society. Filadélfia: Temple University Press, 1989b.

Frontier land: collective actions between actors and systems. In: Diani, Mario \& Eyerman, Ron (orgs.). Studying collective action. Londres: Sage, 1992, p. 238-258.

Challenging codes: collective action in the information age. Cambridge: Cambridge University Press, 1996.

Miller, Byron. Geography and social movements. Minneapolis: Minnesota University Press, 2000.

Neveu, Érik. Sociologie des mouvements sociaux. Paris: La Decouverte, 1996.

Oberschall, Anthony. Social conflict and social movements. Nova Jersey: Prentice-Hall, 1973.

Popper, Karl. The logic of scientific discovery. Londres: Hutchinson, [1934] 1959.

Santos, Boaventura de Sousa. Pela mão de Alice: o social e o político na pós-modernidade. São Paulo: Cortez, 2005.

Santos, Milton. Da totalidade ao lugar. São Paulo: Edusp, 2002. Seoane, José; Taddei, Emilio \& Algranti, Clara. Las nuevas configuraciones de los movimientos populares en América Latina. In: Borón, Atilio \& Lechini, Gladys (orgs.). Política y movimientos sociales en un mundo hegemónico. Buenos Aires: Clacso, 2006, p. 227-250. 
Soja, Edward. Postmodern geographies: the reassertion of space in critical social theory. Londres: Verso, 1989.

Stavenhagen, Rodolfo. Decolonizing applied social sciences". Human Organization, 1971, 30/4, p. 333-357.

Stuart, Elden. Mapping the present: Heidegger, Foucault and the project of a spatial history. Londres: Continuum, 2001.

Svampa, Maristella. Cambio de época: movimientos sociales y poder político. Buenos Aires: Clacso/Siglo XXI, 2008.

Movimientos sociales, matrices socio-políticas y nuevos escenarios en América Latina. Working Papers, 2010, 1, Universität Kassel, p. 1-26.

Tarrow, Sidney. Struggling to reform: social movements and policy change during cycles of protest. Occasional Paper, 1985, 15. Western Societies Program, Center for International Studies. Ithaca: Cornell University.

Power in movement. Cambridge: Cambridge University Press, 1994.

. Confessions of a recovering structuralist. Mobilization: An International Quarterly, 2003, 8/1, p. 134-141.

Charles Tilly and the practice of contentious politics. Social Movement Studies, 2008, 7/3, p. 225-246.

. O poder em movimento. Petrópolis: Vozes, 2009.

Global, conventional and warring movements and the suppression of contention. Themes in contentious politics research. Política \& Sociedade, 2011, 10/18, p. 25-49.

Strangers at the gates. Cambridge: Cambridge University Press, 2012.

Tilly, Charles. The vendée. Cambridge: Harvard University Press, 1964.

(org.). The formation of national states in Western Europe. Princeton: Princeton University Press, 1975.

Getting it together in Burgundy. Theory and Society, 1977, 4, p. 479-504.

From mobilization to revolution. Nova York: Random House, 1978.

As sociology meets history. Nova York: Academic Press, 1981. 
Big structures, large processes, huge comparisons. Nova York: Russel Sage, 1984.

. Coerción, capital y los Estados europeos, 990-1990. Madri: Alianza, 1992.

. Democracy is a lake. In: Andrews, George Reid \& Chapman, Herrick (orgs.). The social construction of democracy. Nova York: New York University Press, 1995.

Spaces of contention. Mobilization: An International Quarterly, 2000, 5/2, p. 135-160.

Contention over space and place. Mobilization: An International Quarterly, 2003, 8/2, p. 221-226.

Social movements: 1768-2004. Boulder, CO: Paradigm Publishers, 2004.

. Trust and rule. Cambridge: Cambridge University Press, 2005.

Democracy. Cambridge: Cambridge University Press, 2007.

. Contentious performances. Cambridge: Cambridge University Press, 2008.

Touraine, Alain. La voix et le regard. Paris: Seuil, 1978.

. O método da sociologia da ação: a intervenção sociológica. Novos Estudos Cebrap, 1982, 1/3, p. 36-45.

Von Bulow, Marisa. Building transnational networks: civil society and the politics of trade in the Americas. Cambridge: Cambridge University Press, 2010.

Zald, Mayer. Looking backward to look forward: reflections on the past and future of the Resource Mobilization Research Program. In: Morris, Aldon \& Mueller, Carol (orgs.). Frontiers in social movement theory. New Haven: Yale University Press, 1992, p. 326-348. 


\section{Palavras-chave: Resumo:}

Ações coletivas; Apesar de sua prolífica obra e importantes contribuições Teorias dos movimentos para as ciências sociais, em particular para a sociologia sociais; Charles Tilly; e a história, e da recente reativação do debate sobre os Confronto político; Sociologia política. movimentos sociais no Brasil, o diálogo sistemático com o autor Charles Tilly ainda é tênue no país. Este artigo oferece uma discussão crítica do seu legado no estudo das ações coletivas, de forma geral, e dos movimentos sociais, de maneira mais específica, a partir de uma tripla direção: primeiro, "com Tilly", resgatando suas contribuições teórico-metodológicas clássicas neste campo; segundo, "contra Tilly", discutindo tanto as principais críticas recebidas e controvérsias com outras teorias, escolas e autores, como a busca de respostas renovadas por parte do autor; e, finalmente, "para além de Tilly", assinalando alguns elementos centrais em sua trajetória coletiva e obra mais recente, para além dos quais é preciso avançar. No decorrer desse percurso histórico e teórico, o texto se engaja em uma discussão mais ampla sobre a reconfiguração das ações coletivas e dos movimentos sociais como campo de pesquisa na atualidade.

\section{Keywords: Abstract:}

Collective actions; Despite his prolific work and relevant contributions to the Social movements theories; Social Sciences, particularly to Sociology and History, and

Charles Tilly; Contentious politics; Political sociology. the recent revival of the debate about social movements in Brazil, a systematic dialogue with the author Charles Tilly is still incipient in the country. This article offers a critical discussion of Tilly's legacy in the study of collective actions, in general, and of social movements, more specifically, divided into three steps: first, "with Tilly", recuperating his classical theoretical and methodological contributions in this field; second, "against Tilly", discussing the most important criticism of his work, controversies with other theories, schools and authors, as well as Tilly's attempts at seeking new answers to his questions; finally, "beyond Tilly", highlighting central elements of his collective trajectory and seeking to reach beyond his most recent work. In the course of its historical and theoretical analysis, this article engages in a broader discussion about the ongoing reconfiguration of collective actions and social movements as a field of study. 